\title{
Non-tariff and overall protection: evidence across countries and over time
}

\author{
Zhaohui Niu $^{1} \cdot$ Chang Liu $^{2} \cdot$ Saileshsingh Gunessee $^{3} \cdot$ Chris $_{\text {Milner }}{ }^{4}$
}

Published online: 9 May 2018

(C) The Author(s) 2018

\begin{abstract}
This paper analyzes the evolution of the incidence and intensity of nontariff measures (NTMs). It extends earlier work by measuring protection from NTMs over time from a newly available database and provides evidence on the evolution of NTMs. In particular, building on Kee et al. (Econ J 119(534):172-199, 2009), this paper estimates the ad valorem equivalents of NTMs for 97 countries at the product level over the period 1997-2015. We show that the incidence and the intensity of NTMs were both increasing over this period, with NTMs becoming an even more dominant source of trade protection. We are also able to investigate the evolution of overall protection derived jointly from tariffs and NTMs. The results show that the overall protection level, for most countries and products, has not decreased despite the fall in tariffs associated with multilateral, regional and bilateral trade agreements in recent decades. We also document an increase in overall trade protection during the recent 2008 financial crisis. Overall, this study sheds light on an underresearched aspect of trade liberalization: the proliferation and increase of NTMs.
\end{abstract}

Keywords Non-tariff barriers $\cdot$ Tariff equivalents $\cdot$ Protection

JEL Classification F13 $\cdot$ F14

Chris Milner

chris.milner@nottingham.ac.uk

1 Beihang University, No. 37 Xueyuan Road, Beijing 100191, China

2 School of Economics, University of Nottingham, 199 Taikang East Road, Ningbo 315100 , China

3 Nottingham University Business School China, 199 Taikang East Road, Ningbo 315100, China

4 School of Economics, University of Nottingham, Nottingham NG7 2RD, UK 


\section{Introduction}

Trade reforms associated with multilateral, regional, bilateral and unilateral agreements in recent decades are seen as having reduced trade protection. This is supported with evidence of the general reduction in tariff rates. For instance, according to the United Nations Conference on Trade and Development (UNCTAD) Trade Analysis and Information System (TRAINS) database, the average tariff rates of agricultural products worldwide have decreased from $17.9 \%$ in 1997 to $10.51 \%$ in 2015 while the average tariff rates for non-agricultural products have decreased from $8.78 \%$ in 1997 to $5.36 \%$ in 2015 .

Yet, tariffs are just one facet of trade protection, with non-tariff measures (NTMs) being non-negligible protectionist trade policy measures. NTMs are defined as policy measures other than ordinary customs tariffs, that can have an economic effect on international trade in goods, change in quantities traded, or prices or both (UNCTAD 2010).

It is important to study and measure NTMs. ${ }^{1}$ First, with the significant reduction in tariffs, including bound tariffs in recent decades, NTMs are an important alternative trade policy measure (see WTO 2012). Indeed, a growing number of countries have adopted NTMs as trade protection measures. As reported by the TRAINS database, in 1997, 1456 product lines were subject to at least one type of NTM for each country, while this number had increased to 2852 product lines by 2015 . Secondly and in light of the growing significance of NTMs, we can revisit important questions such as the impact of trade protectionism on socio-economic outcomes such as trade, growth, poverty and firm productivity (Kee et al. 2009). While tariffs are impediments to trade, some NTMs have ambiguous effects on trade. For instance, quotas and voluntary export restraints as NTMs are unambiguously seen as barriers to trade, but sanitary and phytosanitary measures (SPS) or technical barriers to trade (TBT), have a less clear cut effect (Ganslandt and Markusen 2001; Aisbett and Pearson 2013). This is due to the fact that though SPS and TBT measures add costs to producers, they may also stimulate consumption because of the higher quality of imports. $^{2}$

Despite the relevance and interest in NTMs, measuring their overall extent or protectiveness has received limited attention in the trade literature. This is not surprising given the challenges to identification and measurement. Indeed, most previous attempts to capture NTMs have taken the form of simple indicators that are not adequately grounded in trade theory or aggregate measures that fail to capture actual trade protection policies (Bowen et al. 2016, p. 52). ${ }^{3}$ One study that attempts

\footnotetext{
1 Interest in studying and measuring trade barriers goes back to the work of Balassa (1965) and Corden (1966), though with a focus on tariffs. See Baldwin (1991), Bora et al. (2002), Deardorff and Stern (1998) and Ferrantino (2006) on the quantification of NTMs.

2 This is the reason we prefer the term non-tariff measure (NTM) to non-tariff barrier (NTB), as nontariff policies doesn't just act as an impediment of trade and have only negative welfare effects. Net trade effect can be positive.

3 The most common approach used to gauge the restrictiveness of NTMs are the frequency index and coverage ratio (Bowen et al. 2016); though they lack a sound theoretical grounding (Kee et al. 2009). Other measures have taken the form of: applied general equilibrium measures, price-based measures,
} 
to define and measure NTMs, including overall trade restrictiveness indicators, is Kee et al. (2009). This study adopts quantity-based measures and ground their work in trade theory (Leamer 1988, 1990; Trefler 1993; Lee and Swagel 1997). They estimate ad-valorem equivalents (AVEs) of NTMs for each country at the tariff line level. The approach is to use a common metric for alternative trade policy instruments, allowing direct comparison with tariffs and measurement of the combined or overall level of trade protection. ${ }^{4}$ They estimate AVEs of NTMs at the product level and on average for 78 developing and developed countries. However, this estimation is carried for only 1 year, 2002 or closest year before 2002 for which data was available. The key finding of the study is that NTMs account for a large portion of trade barriers and restrictiveness across most countries.

This present paper is in that tradition of the empirical work that takes direct measures of the incidence of NTMs and infers price (or trade) effects resulting from the presence or not of NTMs. There is an alternative strand of the literature which uses an indirect approach, inferring the existence of NTMs from unexpected price or trade gaps or anomalies (e.g. Bradford 2003; Ferrantino 2006). Given the availability of improved information across countries and over time on the incidence of NTMs, we prefer a direct approach. This direct approach might be applied to either bilateral or multilateral trade flows. Both Bouet et al. (2008) and Bratt (2017) for instance use a bilateral approach (for a single point in time), allowing the impact on trade of NTMs to vary across exporter-importer country pairings. An appropriate gravity modelling framework allows such analysis to deal with the multilateral resistance (the influence of all other countries) on each bilateral trade flow. Given that we wish to measure protection over time, we deliberately reduce the non-trivial data challenges of also measuring AVEs on a bilateral basis and use data on tariffs, NTM incidence and import elasticities measured on a multilateral basis. In doing so, the need to model multilateral resistance effects is side-stepped and the presentational challenge of summarizing bilateral AVEs of NTMs across trade partners and time is also reduced. The multilateral approach also allows direct comparison with the earlier work of Kee et al. (2009).

A limitation of Kee et al. (2009) is that the paper provides trade protection estimates for a single year, 2002. The analysis cannot comment on the evolution of protection from NTMs and the overall protection over time. For instance, with the gradual tariff reduction, what happened to NTM protection levels up to and since 2002? How has overall trade protection levels changed over time and how has NTMs changed relative to tariffs? How have these changes varied across countries and country groupings, and across products and product groupings?

\footnotetext{
Footnote 3 (continued)

and gravity-based measures (see Bradford 2003; Dean et al. 2009; Disdier and Marette 2010). Even these measures have issues, including their lack of tight links to trade theory and precise definition of NTMs and trade restrictiveness.

${ }^{4}$ This follows the conceptual work of Anderson and Neary $(1994,1996)$ where trade distortions are captured in various ways.
} 
In the present work we offer insight on such questions, with improved data on the classification of NTMs and comparing countries for specific years and over time. We are able to comment on the impact of some recent changes and events, such as the 2008 financial crisis. This is salient, as in subsequent work, Kee et al. (2013) estimate the change in trade restrictiveness between 2008 and 2009 using indices based on the most-favored nation (MFN) tariff rate and antidumping measures, for a wide range of countries. They conclude that increased protection from this restricted set of trade policy instruments accounted for a very small proportion of the decline in trade in the immediate post-financial crisis period. One may legitimately be concerned about whether this conclusion is fashioned by the limited coverage of NTMs and by the limited time period.

The goal of this paper is to study the evolution of trade protection levels over time, in particular that due to NTMs. Two questions are addressed: Has the level of NTM barriers followed the same downward trend as tariff barriers during recent decades, or have NTM barriers actually increased? Additionally, how has the overall level of trade protection (i.e. from tariffs and NTMs) changed over time?

Our ability to estimate NTM protection levels over time in a consistent manner stems from the use of a newly available database on NTMs. This dataset is based on a new system of classification of NTMs, namely UNCTAD's Multi-Agency Support Team (MAST). Previous studies on NTMs, including Kee et al. (2009), adopted UNCTAD's previous system of classifying NTMs, dubbed the Trade Control Measures (TCMCS). Using the UNCTAD-MAST, as opposed to the UNCTAD-TCMCS, makes it possible to comprehensively analyze NTMs for different countries over time. This new data provides improved coverage of measures and captures NTMs in greater depth and breadth.

This paper estimates the AVEs of NTMs at the Harmonized System (hereafter HS) 6-digit product level for 97 countries over the period 1997-2015, following the methodology of Kee et al. (2009). To be precise we estimate protection levels at 3 year intervals from 1997 to 2015 (i.e., 1997, 2000, 2003, 2006, 2009, 2012 and 2015), making it possible to track and compare the evolution of AVEs of NTMs and tariff levels. Such information is of interest to both scholars and policy makers, including international agencies such as the WTO, World Bank and IMF. In particular aid allocation by the latter two agencies is often conditional on trade reforms where such indicators of trade protection take a key role.

This paper is organized as follows. Section 2 sets out the methodology for estimating AVEs of NTMs, while Sect. 3 provides information on the data sources and descriptive information on the incidence and coverage of NTMs. Section 4 outlines the evidence on the estimates of NTM protection levels across different dimensions and the evolution of overall trade protection. Finally, we conclude in Sect. 5.

\section{Estimation strategy}

This paper adopts the methodology of Kee et al. (2009) and applies it at discrete points over time. It estimates country-product regressions for each year that information on incidence of core NTMs is available. Then, combining the AVEs of NTMs 
and tariff equivalents, we obtain total protection levels. This allows us to study all three measures over time.

The base model is:

$$
\ln m_{n c}-\varepsilon_{n c} \ln \left(1+t_{n c}\right)=\alpha_{n}+\sum \alpha_{n k} C_{c}^{k}+\beta_{n c}^{\text {Core }} \text { Core }_{n c}+\beta_{n c}^{D S} \ln D S_{n c}+\kappa_{n c}
$$

where $m_{n c}$ is the import volume for product $n$ by country $c .^{5}$ The world price is assumed exogenous at unit price for all goods. Therefore, $m_{n c}$ is the normalized import quantity. $\alpha_{n}$ is the product line intercept, which captures factors related to product $n$ that do not change across countries. Core $_{n c}$ is a dummy for core NTM for product $n$ in country $c . D S_{n c}$ represents the agricultural domestic support, in millions of dollars, reported by WTO for member countries for each product.

$t_{n c}$ represents the ad-valorem tariff on product $n$ in country $c$ and $\varepsilon_{n c}$ is the import demand elasticity for product $n$ in country $c$ which is assumed to be unchanged over time. This constrained import demand function incorporates the tariff effect on import quantity on the left hand side of the equation to deal with the endogeneity of tariffs. Furthermore, it models the NTM effect as an additional quantity restriction caused by the presence of the non-tariff barrier. ${ }^{6}$ Given this constrained specification may lead to possible misspecification errors in the regression equation, the error term $\kappa_{n c}$ is in fact an adjusted error term from the unconstrained regression (i.e., with tariff as explanatory variable). We use the standard White correction for heteroscedasticity as this error term is likely to be heteroscedastic.

$\beta_{n c}^{C o r e}$ and $\beta_{n c}^{D S}$ are coefficients capturing quantity effects for the presence of core NTMs and domestic support that vary by country and product. $C_{c}^{k}$ controls for the $k$ th country's characteristics. In the regressions, the country-characteristics include GDP, labor/GDP, capital/GDP, and land/GDP as well as two gravity variables, a dummy for islands and the weighted distance to the world market. $\alpha_{n k}$ are the coefficients for these country-specific characteristics.

For the above base model (1) we impose some structure on $\beta_{n c}^{\text {Core }}$ and $\beta_{n c}^{D S}$ to allow for product and country variations by decomposing them into country specific factors and tariff line specific factors (i.e., the coefficients for core NTM and domestic support have country $c$ and tariff-line $n$ dimensions). This decomposition allows the estimation to take full advantage of the data variation without running out of degrees of freedom. This yields the following specification:

\footnotetext{
5 The zero trade issue arises here. In the case when the country does not report imports for a specific product, the import volume should be defined as zero. However, $\ln m_{n c}$ would not be defined when $m_{n c}=0$. We follow Kee et al. (2009) and add 1 to all $m_{n c}$ values recorded as having a zero import value.

6 Where the NTM is the binding constraint it will strictly account for all of the quantity effect, but we assume that in the absence of the NTM the tariff barrier would remain.
} 


$$
\begin{aligned}
\ln m_{n c}-\varepsilon_{n c} \ln \left(1+t_{n c}\right)= & \alpha_{n}+\sum_{k} \alpha_{n k t} C_{C}^{k}+\left(\beta_{n}^{\text {Core }}+\sum_{k} \beta_{n k}^{\text {Core }} C_{c}^{k}\right) \text { Core }_{n c} \\
& +\left(\beta_{n}^{D S}+\sum_{k} \beta_{n k}^{D S} C_{c}^{k}\right) \ln D S_{n c}+\kappa_{n c}
\end{aligned}
$$

The tariff line specific factors come from the $\beta_{n}^{\text {Core }}$ and $\beta_{n}^{D S}$ terms, while the country specific factors come from the $\beta_{n k}^{\text {Core }} C_{c}^{k}$ and $\beta_{n k}^{D S} C_{c}^{k}$ terms. The latter are simply interaction country-specific variables, $C_{c}^{k}$, which can be seen to measure the $k$ th country factor endowment. Thus, $\beta_{n k}^{\text {Core }}$ measures how the $k$ th country specific endowment affects the adjusted import volume for product $n$ in country $c$ when a core NTM is present. Similarly, $\beta_{n k}^{D S}$ measures how the $k$ th country specific endowment affects the adjusted import volume for product $n$ in country $c$ when $\ln \left(D S_{n c}\right)$ increases by $1 \%$.

To tackle the endogeneity problem arising from the incidence of NTMs being influenced by import volume at the product level, exports and the change of import volume over the last period at the product level are included as instrumental variables for import volume, following Kee et al. (2009). This is based on the assumption that exports and imports from the last period are not affected by future import policy measures (tariff and NTMs) but they are correlated with the import of the product in the present period. These instrumental variables are available at a disaggregated product level and have been used in the literature (see Kee et al. 2009).

As an alternative to lagged trade volumes, the GDP-weighted average of the core NTM dummies at product level for the five geographically closest countries is also used as an alternative instrument for the core NTM incidence dummy. Similarly, the domestic support for product $n$ in country $c$ is also instrumented with the GDP-weighted average of domestic support for product $n$ of the five geographically closest countries. This is based on the notion that geographically close countries may share cultural and legal similarities and thus NTM policies may be similar. A country's NTMs may be influenced by NTMs in neighboring economies, but not its imports. This is a safe assumption as long as an individual country's NTMs don't affect world prices and in turn imports.

To model core NTMs as an endogenous dummy variable, we use the HeckmanMaddala treatment effect regression model. We run a Probit regression model for each product line where the incidence of a core NTM is instrumented using GDP-weighted NTMs for five closest neighbors, exports and lagged change in imports. The inverse Mills ratio obtained through this estimation is then included in our estimation of specification (2), as a control variable. With domestic support being a continuous variable, its instrumentation follows a least squares estimation with the above instruments also used.

Exponential functions to express the coefficients for $\beta_{n c}^{\text {Core }}$ and $\beta_{n c}^{D S}$ are applied and regressions are based on nonlinear least square methods. Therefore, the coefficients for core NTMs and domestic support are constrained to be non-positive, requiring that the imposition of core NTMs and domestic support restricts imports. This is because 
NTMs are assumed to be restrictive in nature and thus expected to exert a negative trade effect. The other merit of this is to smooth the observations and moderate the effect of any extreme values. Later as a robustness check we relax this assumption.

Our final regression model, after substituting for these exponentials of $\beta$, takes a non-linear form:

$$
\begin{aligned}
\ln m_{n c}-\varepsilon_{n c} \ln \left(1+t_{n c}\right)= & \alpha_{n}+\sum_{k} \alpha_{n k} C_{C}^{k}+\left(-e^{\left(\beta_{n}^{\text {Core }}+\sum_{k} \beta_{n k}^{\text {Core }} C_{c}^{k}\right)}\right) \text { Core }_{n c} \\
& +\left(-e^{\left(\beta_{n}^{D S}+\sum_{k} \beta_{n k}^{D S} C_{c}^{k}\right)}\right) \ln D S_{n c}+\kappa_{n c}
\end{aligned}
$$

Therefore, non-linear squares is required to estimate the above regression and $\beta_{n c}^{\text {Core }}$.

To allow a comparison with tariffs, NTMs need to be converted and quantified into ad-valorem equivalents (AVEs) of NTMs using the estimated coefficients for $\beta_{n c}^{\text {Core }}$ as follows:

$$
\operatorname{ave}_{n c}^{\text {Core }}=\frac{1}{\varepsilon_{n, c}} \frac{\partial \ln \mathrm{m}_{n c}}{\partial \text { Core }_{n c}}=\frac{e^{\beta_{n c}^{\text {Core }}}-1}{\varepsilon_{n c}}
$$

The AVEs of NTMs and domestic support are estimated for 5009 product lines for 97 countries at 3 year intervals over the period 1997-2015, specifically for 1997 , 2000, 2003, 2006, 2009, 2012 and 2015. We adopt this 3-year span because we average the continuous variables like trade flows and domestic support to smooth out year-specific shocks. 5009 regressions are run for each of these years to estimate import functions at the product or tariff level on a consistent basis.

Finally, overall trade protection, $T_{n c}$, is made up of AVE of NTMs which country $c$ imposes on product $n$, ave ${ }_{n c}$, and applied tariff by economy $c$ on imports of product $n, t_{n c}$. Thus, this overall protection on trade imposed by country $c$ on imports of product $n$ is depicted as:

$$
T_{n c}=a v e_{n c}+t_{n c} .
$$

Despite the availability of a time dimension in our data we eschew formal dynamic modelling. Our goal is to investigate changes in protection between discrete points in time. We seek to circumvent the need for dynamic modelling that would be required if using continuous, annual data. ${ }^{7}$ The use of repeated, static modelling also allows for direct comparison with the earlier work of Kee et al. (2009). This notwithstanding some robustness checks are reported later in the paper, when we replace the contemporaneous trade policy variables with their lagged values.

\footnotetext{
${ }^{7}$ Formal dynamic modelling of protection effects on trade over time is a direction for possible further work in this area.
} 


\section{Data and descriptives}

\subsection{Data sources}

The trade flow data comes from the COMTRADE database spanning 1995-2015 at HS 6-digit level. The import volume data is used to build the left-hand side variable, while the export volume data is used as one of the instrumental variables. To eliminate year-specific shocks, trade flow data is averaged for continuous 3 year periods. The other merit of such smoothing procedure is the tendency for trade flows to trend. Trade volume is measured in 1000 dollars (units of dollar are unified into dollar in year 2015) and deflated by the Consumer Price Index (hereafter CPI) with 1997 as base year. The CPI data are obtained from the World Development Indicators (WDI) database of the World Bank.

The tariff data is the effectively applied tariff rate and is drawn from the UNCTAD TRAINS database at the HS 6-digit product level. This is for the years 1997, 2000, 2003, 2006, 2009, 2012 and 2015. If the tariff data for these years are missing in the database, data from previous years are adopted.

We use import demand elasticities at the 6-digit HS level for 117 countries estimated by Kee et al. (2008). These import demand elasticities correspond to the initial years of our sample and thus are assumed to be constant for the sample period.

The source for the NTM data is also UNCTAD's TRAINS. There is a newly constructed database for NTMs using a new classification, the UNCTAD-MAST classification for NTMs. The new database is consistently updated at detailed 6-digit HS product level and runs over several years. Out of the 150 types of NTM measures, the measures considered as core NTMs are: Price control measures (TRAINS M3 code F1-F3), Quantity Restrictions (TRAINS M3 code A1, B1, E1-E3, G33), Monopolistic measures (TRAINS M3 code $\mathrm{H}$ ) and technical measures (TRAINS M3 code A, B, C). ${ }^{8}$ The core NTM variable takes the value of 1 if any of the above measures are in place for a 6-digit tariff line level, and 0 otherwise.

The domestic support data is obtained from WTO members' notifications between 1995 and 2009 at the product level. Similar to the trade flow data, the domestic support data is averaged for each three-year span at the product level and measured in 1000 dollars. If there is no information on domestic support for a product, the data is treated as zero. ${ }^{9}$ There are altogether 113 products at 6-digit HS tariff line with domestic support data reported by WTO members.

The country characteristics data mainly comes from the WDI database for 1996-2015. Variables measured in nominal terms, namely GDP and capital flows, are deflated by the GDP deflator.

\footnotetext{
${ }^{8}$ For the selection of core NTMs, this paper combines information from: (1) the core NTM definition in the Kee et al. (2009) paper and the corresponding code in M3 nomenclature; (2) The statistical characteristics of the NTMs data, that is, measures take up altogether over $85 \%$ of the overall NTMs; (3) the information the author was able to get from contacting UNCTAD directly.

${ }^{9}$ This is a safe assumption as the database only covers domestic support if in effect and thus reported to WTO. This strategy is also applied in Kee et al. (2009) and Hoekman et al. (2004).
} 


\subsection{Summary descriptives on NTMs}

We first summarize information on the incidence of NTMs from the new UNCTADMAST database. There are over 16 categories of different NTMs, among which this section focuses on the most influential ones, namely price control measures, quantity control measures, technical measures and monopolistic measures.

Following Nicita and Gourdon (2013), we measure frequency using the following index:

$$
F_{c t}=\left[\frac{\sum D_{n c t} M_{n c t}}{\sum M_{n c t}}\right],
$$

where $F_{c t}$ is the frequency index in country $c$ at time $t$ and $M_{n c t}$ is the dummy for the existence of non-zero import for product $n$ in country $c$ at time $t$. $D_{n c t}$ is the dummy for core NTMs meaning the existence of core NTMs for product $n$ in country $c$ at time $t$. The frequency index summarizes the percentage of products affected by at least one type of core NTMs. Measured frequency lies between 0 and 1, with higher values indicating a higher frequency of core NTMs.

Alternatively, we summarize the use of NTMs using the following coverage ratio:

$$
C_{c t}=\left[\frac{\sum D_{n c t} V_{n c t}}{\sum V_{n c t}}\right],
$$

where $V_{n c t}$ is the import volume of product $n$ in country $c$ at time $t$ and the other variables are the same as before. The coverage ratio measures the share of imports subject to core NTMs, with a higher value indicating greater coverage by core NTMs.

Figure 1 reports frequency indices and coverage ratios for the four types of core NTMs for our sampled countries and specified years over the period of 1997-2015. It shows that there was an overall increase in the frequency and coverage of each type of NTMs, indicating an increasing proportion of products and imports that were subject to technical measures, quantity restrictions, price controls and monopolistic measures. In each year, technical measures (i.e. measure 4 in the graph) have the highest frequency index and coverage ratio, compared with other measures, indicating that technical measures are the most widespread used measures and with their importance growing over time. Following technical measures, the ranking of the other measures in terms of importance is: quantity control measures (measure 2 in the graph), price control measures (measure 1) and lastly monopolistic measures (measure 3). These three types of NTMs also affect a broader range of products over the period from 1997 to 2015.

As shown in Table 1, quantity control and technical measures are largely applied in high-income OECD countries. The incidence for the two measures rose from 1997 (the frequency index is 0.05 and 0.27 respectively) to 2015 (the frequency index is 0.52 and 0.69 ). The incidence of these measures significantly increased after 

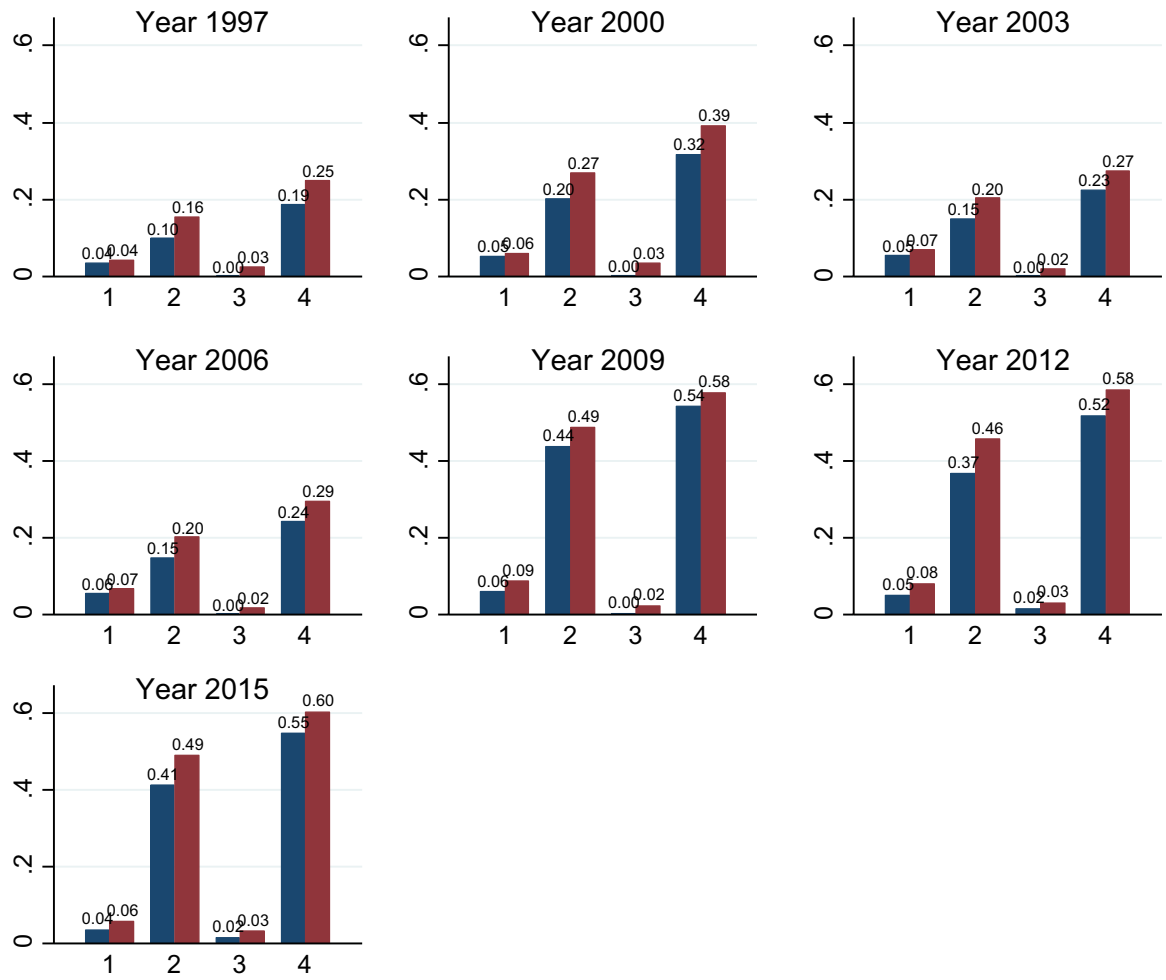

\section{Frequency Index $\quad$ Coverage ratio}

Source: WITS(2016)

1-Price Control,2-Quantity Control, 3-Monopolistic Measures, 4-Technical Measures

Fig. 1 Incidence of different types of NTM over time (1997-2015)

2009, suggesting that many OECD countries turned to more protective trade policies after the financial crisis. The high-income non-OECD countries also showed a similar trend. Compared with other income groups, the high-income countries are more likely to apply technical measures.

For upper middle-income countries, technical measures are the most important and most used form of NTM, followed by quantity control measures and price control measures. Price control measures are more influential than in high-income countries. The incidence of the four types of core NTMs generally increased from 1997 to 2012, and slightly declined in 2015.

In lower middle-income countries, technical measures are the most important NTMs and the coverage was increasing over time to nearly half of the imported products in 2015. The incidence of quantity control measures continued to decrease, while price control measures became less frequently applied. For low-income countries, the incidence of core NTMs, namely price control measures, quantity control measures or technical measures also increased over time. 


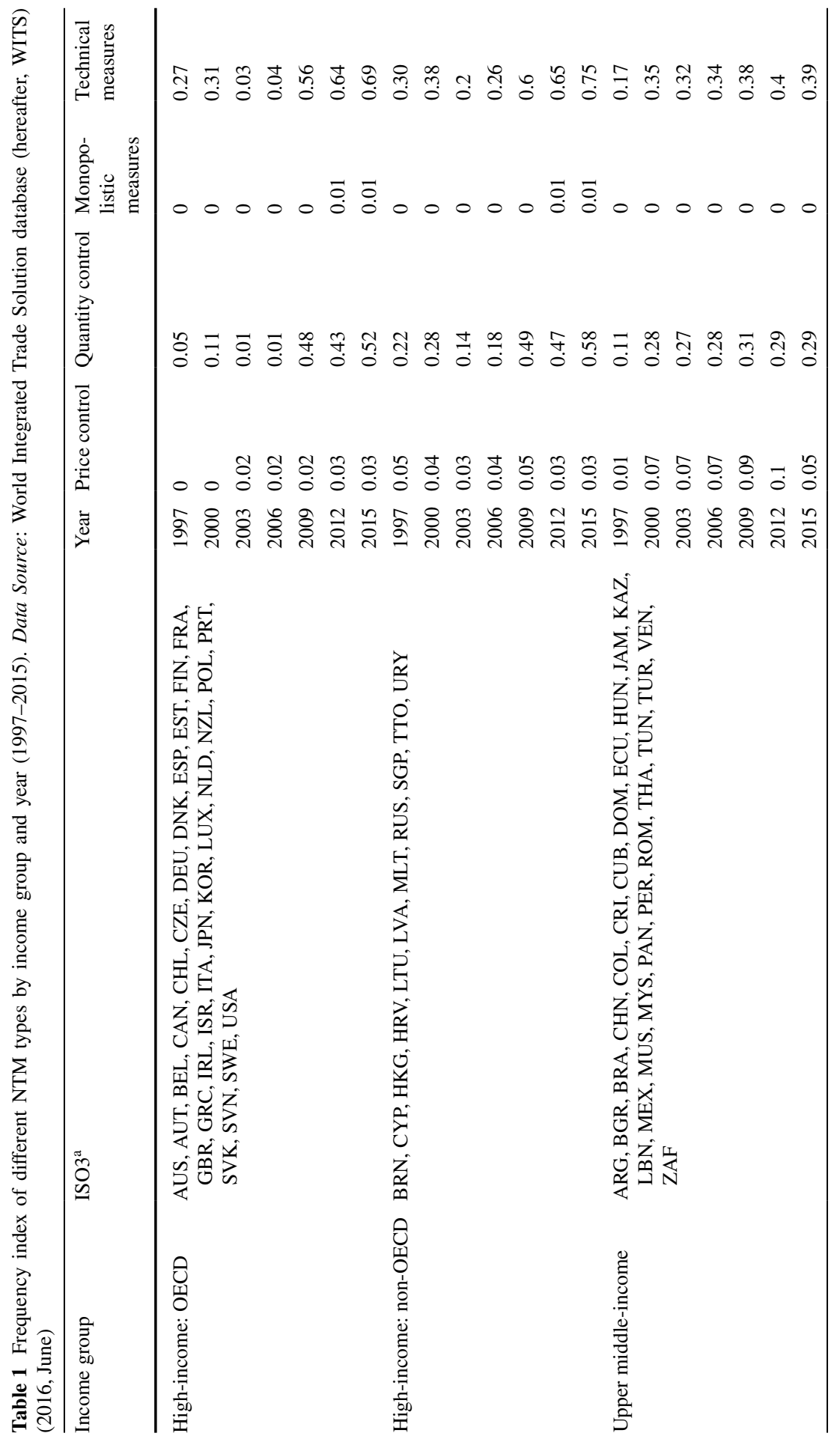




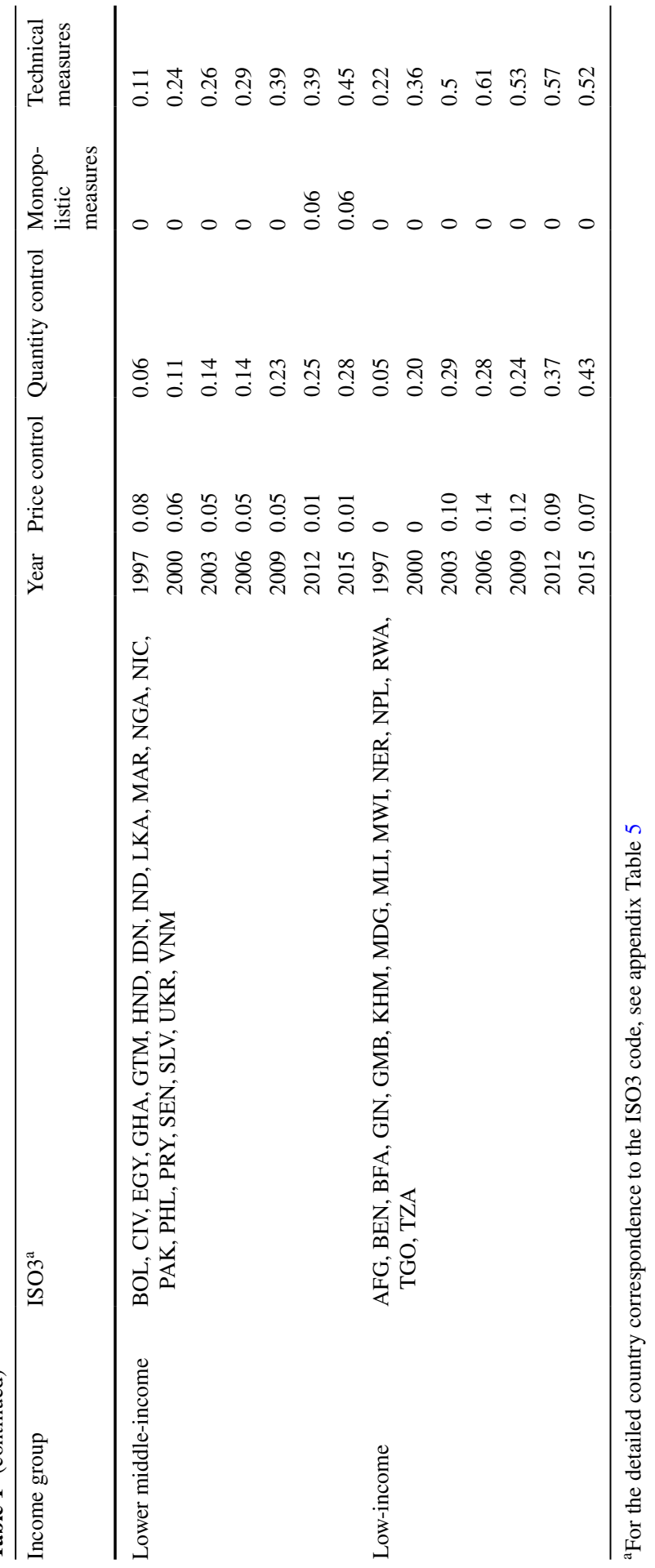


Table 2 Frequency index of different NTM types across economic sectors (1997-2015)

\begin{tabular}{|c|c|c|c|c|}
\hline Industry name & Price control & Quantity control & $\begin{array}{l}\text { Monopo- } \\
\text { listic } \\
\text { measures } \\
(4)\end{array}$ & $\begin{array}{l}\text { Technical } \\
\text { measures } \\
(5)\end{array}$ \\
\hline \multicolumn{5}{|l|}{ Agricultural product (HS0 industry 1-24) } \\
\hline Live animals (1-5) & 0.06 & 0.51 & 0 & 0.6 \\
\hline Vegetable products $(6-14)$ & 0.06 & 0.5 & 0.01 & 0.61 \\
\hline Fats and oils (15) & 0.08 & 0.38 & 0.01 & 0.54 \\
\hline Prepared foodstuffs (16-24) & 0.06 & 0.41 & 0.01 & 0.59 \\
\hline Agricultural mean & 0.07 & 0.45 & 0.0075 & 0.59 \\
\hline \multicolumn{5}{|l|}{ Manufacturing product (HS0 industry 25-97) } \\
\hline Mineral products $(25-27)$ & 0.04 & 0.2 & 0.02 & 0.24 \\
\hline Chemical products (28-38) & 0.05 & 0.32 & 0.01 & 0.38 \\
\hline Rubber and plastics (39-40) & 0.05 & 0.18 & 0.01 & 0.31 \\
\hline Raw hide and skins (41-43) & 0.04 & 0.27 & 0 & 0.37 \\
\hline Wood (44-46) & 0.06 & 0.25 & 0 & 0.37 \\
\hline Paper (47-49) & 0.05 & 0.12 & 0 & 0.23 \\
\hline Textile (50-63) & 0.05 & 0.18 & 0.01 & 0.37 \\
\hline Footwear (64-67) & 0.04 & 0.21 & 0 & 0.36 \\
\hline Stone and cement $(68-70)$ & 0.05 & 0.16 & 0 & 0.29 \\
\hline Base metals (71-83) & 0.05 & 0.2 & 0 & 0.31 \\
\hline $\begin{array}{l}\text { Machinery and electrical equipment } \\
(84-85)\end{array}$ & 0.04 & 0.25 & 0.01 & 0.39 \\
\hline Motor vehicles (86-89) & 0.04 & 0.27 & 0.02 & 0.41 \\
\hline Optical and medical instruments (90-92) & 0.05 & 0.25 & 0.01 & 0.34 \\
\hline Miscellaneous goods (93-97) & 0.05 & 0.18 & 0 & 0.29 \\
\hline Manufacturing mean & 0.05 & 0.22 & 0.01 & 0.33 \\
\hline
\end{tabular}

The numbers in brackets in column 1 are the coding for products at 2-digit level in HS1988/92 classification. Numbers in Column 2-5 are frequency indices calculated based on Eq. 5. The subscription $\mathrm{j}$ in the equation refers to sector $\mathrm{j}$ in this calculation. Therefore, the number measures the probability of the sector affected by certain type of NTM. It should also lie between 0 and 1 and the higher it is, the larger the proportion of products in this sector that are affected by NTMs

Table 2 reports the coverage of different types of NTMs for different sectors and industries for our sample of countries over the whole period. Sectors are divided according to the HS code at the 2-digit level. Generally, the frequency or incidence of core NTMs was greater for agricultural products than for manufacturing goods. Whether the estimated AVEs of NTM for agricultural products are higher on average than for manufacturing products depends on the extent to which imports are restricted by NTMs in the two sectors.

The use of different types of NTM varies across industries. For agricultural products, technical measures are the most frequently applied. This is consistent with expectations, as some technical measures such as sanitary and phytosanitary 
Table 3 Average AVE estimates, tariffs and overall protection

\begin{tabular}{|c|c|c|c|c|c|c|c|c|}
\hline \multirow{3}{*}{$\begin{array}{l}\text { Year } \\
\text { (1) }\end{array}$} & \multirow{3}{*}{$\begin{array}{l}\text { Observa- } \\
\text { tions } \\
\text { (2) }\end{array}$} & \multirow{3}{*}{$\begin{array}{l}\text { Country } \\
\text { (3) }\end{array}$} & \multicolumn{3}{|c|}{ Simple average } & \multicolumn{3}{|c|}{ Import-weighted average } \\
\hline & & & AVE & Tariff & Overall & AVE & Tariff & Overall \\
\hline & & & (4) & (5) & (6) & (7) & (8) & (9) \\
\hline 1997 & 128,459 & 37 & $0.20(0.60)$ & $0.12(0.26)$ & $0.32(0.66)$ & $0.22(0.10)$ & $0.10(0.05)$ & $0.31(0.11)$ \\
\hline 2000 & 150,905 & 46 & $0.38(0.77)$ & $0.12(0.14)$ & $0.50(0.79)$ & $0.29(0.12)$ & $0.10(0.07)$ & $0.38(0.13)$ \\
\hline 2003 & 317,949 & 83 & $0.27(0.64)$ & $0.08(0.21)$ & $0.35(0.68)$ & $0.32(0.26)$ & $0.11(0.10)$ & $0.43(0.26)$ \\
\hline 2006 & 338,830 & 88 & $0.22(0.64)$ & $0.06(0.15)$ & $0.28(0.66)$ & $0.25(0.21)$ & $0.10(0.10)$ & $0.34(0.20)$ \\
\hline 2009 & 342,824 & 92 & $0.52(0.85)$ & $0.05(0.15)$ & $0.57(0.87)$ & $0.51(0.24)$ & $0.08(0.08)$ & $0.58(0.23)$ \\
\hline 2012 & 346,694 & 95 & $0.33(0.71)$ & $0.05(0.14)$ & $0.38(0.73)$ & $0.34(0.20)$ & $0.04(0.03)$ & $0.38(0.21)$ \\
\hline 2015 & 332,616 & 92 & $0.57(0.95)$ & $0.05(0.14)$ & $0.62(0.96)$ & $0.51(0.24)$ & $0.04(0.03)$ & $0.54(0.25)$ \\
\hline
\end{tabular}

Standard errors in parentheses

measures are targeted in particular at agricultural products. About $60 \%$ of the agricultural products were affected by technical measures, while quantity control measures covered $45 \%$ of the products. Price control measures such as antidumping measures and countervailing measures affected $7 \%$ of the agricultural products.

The distribution differs substantially for manufacturing products. For some industries, the incidence of NTMs was quite intensive, such as Chemical products (industry 28-38), Machinery and Electrical equipment (industry 84-85), Motor vehicles (industry 86-89), technical measures cover about $40 \%$ of the import of these products and quantity control measures influence about $30 \%$ of these products. Some industries such as paper (industry 47-49) are less likely to be affected by NTMs in general. Less than $25 \%$ of products in these industries are affected by technical measures, price control measures and quantity control measures.

\section{Estimation results}

\subsection{AVE of NTMs and overall protection}

We run 5009 regressions based on specification (3), for each HS 6-digit product level, to estimate the tariff equivalent of core NTMs for 5009 imported products of 97 countries (28 EU countries are estimated separately), for each of the six points in time over the period 1997-2015. The average $\mathrm{R}^{2} \mathrm{~s}$ of these regressions was 0.46 , with a median of 0.43 and maximum of 0.99 . Less than $1 \%$ of the adjusted $\mathrm{R}^{2} \mathrm{~s}$ had a negative sign. Therefore, the fit of these regressions was generally satisfactory. The detailed product level estimates for all countries and years is available on the Links (data links) section of the GEP research centre website at: https://www.nottingham .ac.uk/gep/links/index.aspx. Here we seek to summarize the findings. 
First, we estimate the AVEs of NTMs, using Eq. (4), across different dimensions. This enables us to compare the AVEs of NTMs with tariffs and overall protection, to assess the evolution of these measures over time.

Table 3 summarizes the average estimated AVEs of NTMs and provides a comparison with the corresponding average tariff and overall protection levels for products and countries over our sample period. A comparison of columns 4-5 identifies that the average AVE of NTMs is markedly higher than the average tariff throughout the period. Tariff rates are broadly decreasing over time, with the unweighted average tariff rate falling from $12 \%$ in 1997 to $5 \%$ in 2015 . By contrast, the average AVE of NTM protection was $20 \%$ in 1997 , and rose (with some fluctuation over time) to $57 \%$ in 2015 . Therefore, NTMs were already a more important source of protection than tariffs at the start of our sample period, and have become even more important sources of trade protection over this period. When weighted by the import volume (columns 7-8), the relative magnitudes of the AVEs and tariff vary slightly, but the conclusion about the relative importance of NTMs and tariffs in overall protection is unaltered. We can conclude from Table 3 that on average the trade barrier effect due to NTMs was much greater than that induced by tariffs. This echoes the finding of Kee et al. (2009) on the dominance of NTMs relative to tariffs, but we further show that this dominance has increased over time.

A similar conclusion about the relative importance of the two trade policy tools can be drawn from an inspection of tariffs and the AVE of NTMs at the product level. Appendix Table 6 summarizes the percentage of product lines for each year and the full sample of countries where the tariff is greater, smaller or equal to the AVE of the core NTMs. At the start of the period, i.e. 1997, the tariff was higher than the AVE in just under $44 \%$ of product lines. By the end of our sample period (i.e., 2015), this was true for only about $27 \%$ of products, as compared to nearly twothirds of products being subject to higher non-tariff than tariff protection.

Appendix Table 5 sets out the average AVE of NTMs for each country, presented in coefficient form, for the years for which information was available. Over the period from 1997 to 2015, the average AVE of NTMs for most countries was increasing in general, though there was variation across countries. Some high income countries such as Japan, Australia and New Zealand are identified as consistently 'low protection' countries. Countries with the highest AVEs of NTM are Morocco, Burkina Faso, Argentina, China, Mali, Niger and Nigeria. All of these are low-income countries. However, there was an increase in average AVEs towards the end of the sample period for a significant number of both low and high income countries. This appears to correspond with the post-financial crisis and the downturn in world trade.

\subsection{NTMs across sectors}

Table 4 reports the distribution of the AVEs of NTMs for different sectors. The AVEs are generally higher for agricultural products than for manufacturing products. There was an increase in the AVEs for most sectors over the period from 1997 to 2009, 
Table 4 Average AVEs of NTMs for Product Groups

\begin{tabular}{|c|c|c|c|c|c|c|c|c|}
\hline \multirow[t]{2}{*}{ Industry } & \multirow[t]{2}{*}{ Industry name } & \multicolumn{7}{|c|}{ Simple average AVEs of NTMs in each year } \\
\hline & & 1997 & 2000 & 2003 & 2006 & 2009 & 2012 & 2015 \\
\hline $1-5$ & $\begin{array}{l}\text { Live animals; animal } \\
\text { products }\end{array}$ & 0.53 & 0.85 & 0.50 & 0.37 & 0.55 & 0.51 & 0.43 \\
\hline $6-14$ & Vegetable products & 0.43 & 0.66 & 0.59 & 0.63 & 0.79 & 0.40 & 0.55 \\
\hline 15 & Fats and oils & 0.46 & 0.52 & 0.65 & 0.45 & 0.92 & 0.36 & 0.46 \\
\hline $16-24$ & Prepared foodstuffs & 0.48 & 0.84 & 0.84 & 0.78 & 1.14 & 0.48 & 0.75 \\
\hline \multicolumn{2}{|c|}{ Agricultural product (1-24) } & 0.48 & 0.72 & 0.65 & 0.56 & 0.85 & 0.44 & 0.55 \\
\hline $25-27$ & Mineral products & 0.20 & 0.24 & 0.36 & 0.29 & 0.43 & 0.37 & 0.51 \\
\hline $28-38$ & Chemical products & 0.20 & 0.35 & 0.43 & 0.38 & 0.70 & 0.31 & 0.45 \\
\hline 40 & Rubber and plastics & 0.21 & 0.27 & 0.26 & 0.22 & 0.31 & 0.25 & 0.68 \\
\hline $41-43$ & Raw hide and skins & 0.17 & 0.55 & 0.37 & 0.42 & 0.35 & 0.31 & 0.47 \\
\hline $44-46$ & Wood & 0.32 & 0.39 & 0.28 & 0.33 & 0.21 & 0.26 & 0.37 \\
\hline $47-49$ & Paper & 0.12 & 0.25 & 0.17 & 0.30 & 0.26 & 0.23 & 0.56 \\
\hline $50-63$ & Textile & 0.17 & 0.40 & 0.34 & 0.32 & 0.36 & 0.42 & 0.61 \\
\hline $64-67$ & Footwear & 0.15 & 0.37 & 0.39 & 0.59 & 0.75 & 0.58 & 0.60 \\
\hline $68-70$ & Stone and cement & 0.12 & 0.25 & 0.33 & 0.22 & 0.31 & 0.27 & 0.39 \\
\hline $72-83$ & Base metals & 0.14 & 0.30 & 0.39 & 0.28 & 0.40 & 0.35 & 0.47 \\
\hline $84-85$ & $\begin{array}{l}\text { Machinery and electrical } \\
\text { equipment }\end{array}$ & 0.15 & 0.37 & 0.46 & 0.21 & 0.50 & 0.34 & 0.61 \\
\hline $86-89$ & Motor vehicles & 0.26 & 0.42 & 0.44 & 0.61 & 0.53 & 0.51 & 0.53 \\
\hline $90-92$ & $\begin{array}{l}\text { Optical and medical } \\
\text { instruments }\end{array}$ & 0.27 & 0.47 & 0.41 & 0.53 & 0.56 & 0.46 & 0.74 \\
\hline $94-96$ & Miscellaneous goods & 0.18 & 0.47 & 0.45 & 0.50 & 0.63 & 0.51 & 0.54 \\
\hline \multicolumn{2}{|c|}{ Manufacturing product (25-96) } & 0.19 & 0.36 & 0.36 & 0.37 & 0.45 & 0.37 & 0.54 \\
\hline
\end{tabular}

(1) Expressed in coefficient form for a balanced sample of countries, 1997-2015. (2) To rule out the possible difference caused by different sample size, this summary only considers country-products with available NTM data for the whole period. Products in some country with missing AVEs of NTMs for some of the 7 panels are not considered. Therefore, there are same number of available AVEs of NTMs for each panel year; (3). Sectors are divided using the same criterion as in Table 2; (4). All of the numbers are approximated to two decimal places

though the increase is most evident in manufacturing. Protection from NTMs is shown to be consistently high within the agricultural sector, but to be much more variable across industries in the manufacturing sector. By the end of the period, textiles, footwear, rubber and plastics, optical and medical instruments, machinery and electrical equipment are the most NTM-protected products in the manufacturing sector.

The comparability of the summary evidence in Table 4 with the evidence from other studies is constrained by a number of factors. Many other studies do not provide evidence over time or they use alternative classifications for identifying the incidence of NTMs or they adopt different metrics to measure the overall extent of NTM barriers or protection. One of the important sources of yearly, summary information over the last decade on policy interventions affecting international trade and other forms of international commercial exchange is the Global 

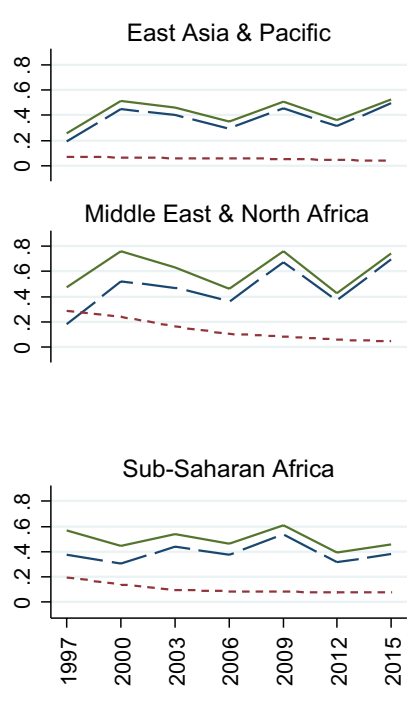

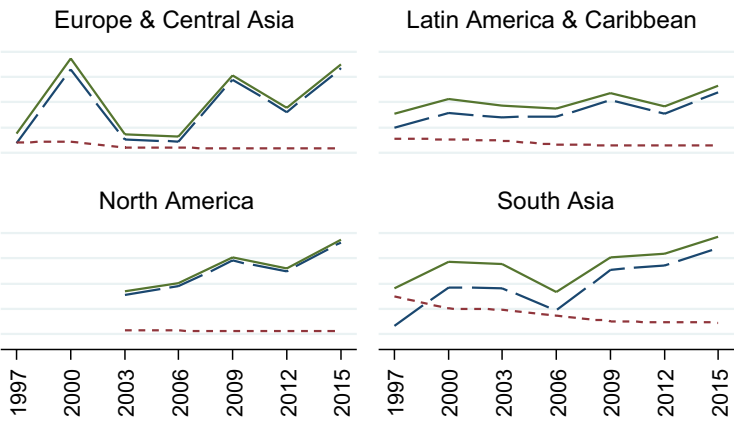

$$
\text { ——- AVE of NTM -...-.-. Tariff — Overall protection }
$$

Fig. 2 Evolution of tariffs, AVE of NTMs and overall protection by region (1997-2015)

Dynamics (GD) database of the Global Trade Alert. ${ }^{10}$ This data (for a larger number of countries than this study) includes count information on the total number of import-related interventions (harmful and liberalizing) implemented each year since 2008 to-date. The interventions include tariffs and the coverage of NTMs is not the same as that used in this study. For the years that are common with the present study, however, there is consistency in the pattern of change in trade protection over time between the evidence in Table 4 and the Global Trade Alert indicators. If one restricts the GD information to interventions reported withinyear (i.e. up to the end of December in each year), both the overall average AVE in Table 4 (for both agriculture and manufacturing) and the count of new harmful interventions (reported in brackets for each year in what follows) fall between 2009 (274) and 2012 (220) and rise between 2012 (220) and 2015 (648). ${ }^{11}$

\subsection{NTMs across countries}

The evolution of AVEs of NTMs, tariffs and overall protection can also be explored with the present results across countries, and in different regions and different income groups, as shown in Fig. 2.

\footnotetext{
${ }^{10}$ http://www.globaltradealert.org/global_dynamics.

11 As in our results, a monotonic upward rise in new interventions/protection is not evident overall in the Global Dynamics data for the whole period up to 2018. There is an upward trend in new interventions up to 2015 and falls in 2016 and 2017 whether or not using data adjusted for reporting lags.
} 
A consistent picture is evident across all the regions; namely one of stable levels or modest declines in average tariff levels, combined with much higher levels of overall protection resulting from much higher levels of NTM than tariff protection. Indeed, the evolution of overall protection in all regions is predominantly driven by changes in NTM protection. Except for Sub-Saharan Africa, overall protection is higher in all regions by the end of the period than at the beginning, and substantially so in the case of some regions (e.g. North America and South Asia). Indeed, in the case of North America, the AVEs of NTMs and overall trade protection rose consistently after 2003. In most regions, other than North America (for which the data starts in 2003), the AVEs of NTMs tended to increase before 2003. The clear exception to this is Europe and Central Asia for which a sharp fall in NTM protection is identified between 2000 and 2003. This may be due to the ending of the Multi-Fiber Agreement (MFA), and the elimination of the quantity restrictions on textiles imports from developing countries by the developed countries. However, after 2006, NTM protection and overall trade protection rose again sharply across all regions. The estimates seem to be capturing the effects of the more protectionist trade policies adopted globally following the 2008 financial crisis. By 2012, we identify some reversal in this more protectionist stance, though NTM and overall protection generally increased again after 2012.

Figure 3 depicts the evolution of tariffs, AVEs of NTMs and overall protection using a classification of countries based on income groupings. The average
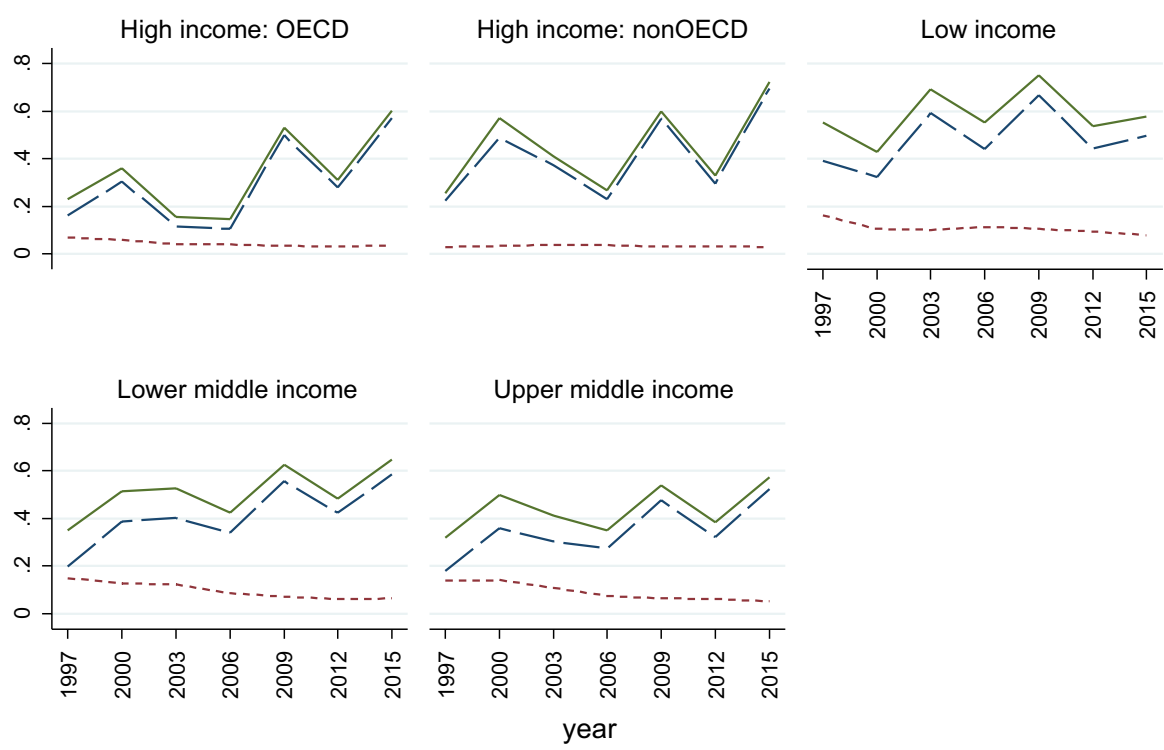

- - - AVE of NTM -.-.-. Tariff Overall protection

Fig. 3 Evolution of tariffs, AVE of NTMs and overall protection by income group (1997-2015) 
tariff for high income countries is significantly lower than in the case of middle and low income countries, but the difference in overall protection between higher and lower income countries declined markedly over the period as protection from NTMs rose more sharply in high income countries (especially the OECD countries and after 2006). Average levels of overall protection in 2015 are identified by this study to be at a tariff-equivalent of about $60 \%$ in both OECD and low income countries. Having changed relatively little over the period in the low income countries but risen sharply, from a little over $20 \%$ at the start of the period, in the case of the OECD countries. Clearly the evolution of tariffs fails completely to reflect the changing stance of trade policy in this period.

\subsection{Comparison with Kee et al. (2009) results}

Appendix Table 7 provides the average AVEs estimates for a comparable set of countries covered by Kee et al. (2009) in their study (i.e., re-estimated here) and this present study, for estimation surrounding 2002 in the former and 2003 in the latter. There are some similarities between the two sets of results. The relative importance of NTMs and tariffs as sources of protection is a feature of both studies; non-tariff being more dominant than tariff protection. This is evident from the average AVEs and tariff levels in both studies. More than half of the product lines subject to core NTMs are identified as being more restricted by NTMs than tariffs in both studies. In addition, the most protected industries (or imports competing with products produced by these industries subject to most restriction) are identified to be similar in both studies. It is also the case that the individual countries with the highest level of NTM protection are identified by both studies to be generally low-income countries.

However, there are also some differences in the average levels of NTM protection across countries in the two studies, despite the common estimation method. It is evident from Table 7 that average AVEs are generally higher for the comparable sample than the present study; only for 24 countries is the average AVE higher in the present study, while it is lower in the case of 54 countries. The simple average AVE across the common set of 82 countries is $29.5 \%$ in the current study and $42.7 \%$ for Kee et al. (2009). These differences are likely to stem from the different datasets on NTM incidence adopted, and the comparison is based on simple averages. Notwithstanding this, both studies reveal the dominance of NTMs relative to tariffs and the importance of non-tariff barriers in determining overall protection levels.

\subsection{Robustness Analysis}

Our base modelling recognizes the possible endogeneity of NTMs. Nonetheless, as a further check, we re-estimated the regressions using the 3-year lags of NTMs and tariffs. The NTM incidence variable continues to be instrumented (now with 3-year lagged instruments). Appendix Tables 8 and 9, and R-squares plot depicted by Appendix Fig. 4, report these additional findings. While the magnitude of the 
average effect differs from the original results (expected given differences across observations), the key point is the non-negligible importance of AVE of NTMs still holds. Looking at the correlation between original and new estimates (see column 3 in Table 8), of the more than 5000+ coefficients estimated, we find a correlation ranging from 0.36 and 0.75 . Furthermore, the R-squares for new estimates mirror those of the original estimates. Table 9 shows the correlations between the incidence of NTMs over time. The high correlation over time indicates persistence in the incidence and non-incidence of NTMs, with the correlation in incidence between any two 'adjacent' points in time being at least over 0.7 and generally over 0.8 . This indicates a 'slow changing NTM variable', where cross-sectional, rather than time, variation tends to drive our results and in turn implying that our instrumented contemporaneous variable is robust.

Next, we re-run the analysis for a balanced sample. Appendix Table 10 and the R-squares in Appendix Fig. 5 report the results in summary for this sample. Although the R-squared graph suggests a slightly lower fit for some regressions, the average effect doesn't differ as much and the correlation between the matched coefficients for the balanced and unbalanced samples is generally high.

Finally, we obtain the AVE of NTMs from estimating the linear specification (2), rather than the non-linear specification (3). Given the difference in specifications and the susceptibility of the means to be affected by extreme values, the R-squares and average AVE of NTMs for the linear and non-linear estimation are not strictly comparable. Therefore, we follow Kee et al. (2009) to find the proportion of estimates AVE of NTMs from the linear specification that are negative (i.e. have a trade promoting effect). We find around $12-18 \%$ of the sample to be so. This is similar to Kee et al. who find $13 \%$ of AVE of NTMs to be negative. Even though specific NTMs, such as sanitary and phytosanitary measures or technical measures, could have positive trade effects under some circumstances, we do not expect the incidence of all core NTMs at the tariff line level to be net trade-promoting for other than a very small proportion of tariff lines. Indeed, even in the case of the unrestricted estimation, the overwhelming majority of NTMs are trade-restricting according to our estimates. In line with Kee et al. (2009), our preferred estimates for comprehensive measurement of the trade effects of non-tariff barriers are those based on a nonlinear estimation method. ${ }^{12}$

\section{Conclusion}

This paper sets out to measure the tariff equivalents of NTMs at specific points in time over the period 1997-2015. Unlike previous studies, these measures are grounded in trade theory and allow for direct comparison with tariffs. This is achieved by applying a consistent data set and estimation method to derive AVEs over time, using the method proposed by Kee et al. (2009). This enables us to explore the evolution of NTMs over time, which is left unaddressed by this earlier study. In particular, we

\footnotetext{
12 Of course, when modelling the trade effects of specific NTMs for specific commodities one may need to give greater weight to evidence from unrestricted estimation methods.
} 
address the questions of how the AVEs of NTMs and the overall trade protection level changed during this period, especially in light of the gradual tariff reductions over the recent decades; including the recent 2008 financial crisis. This is achieved by adopting a newly assembled database for NTMs, namely UNCTAD-MAST, using a consistent classification of NTMs and consistent estimation method.

A descriptive analysis of the NTMs from this data indicates that the overall incidence of the core NTMs, namely price controls, quantity restrictions, monopolistic measures and technical measures increased over the period from 1997 to 2015. The most widely applied NTMs each year were technical measures, followed by quantity restrictions, price control and monopolistic measures.

The regression analysis derived estimates of AVEs of NTMs. They are compared to tariff measures and also used to construct measures of overall trade protection. NTMs are revealed to be the more dominant trade barrier, with their importance growing over the sample period. Thus, overall trade protection is in fact on the rise, despite the apparent, gradual trade liberalization associated with tariff reductions. Further, NTM and overall protection peaked in 2009, in the aftermath of the 2008 financial crisis. This is suggestive of a rise in protectionist tendencies after the 2008 financial crisis, contrary to earlier findings of no pervasive increase in protectionism (Kee et al. 2013).

The AVEs of NTMs vary significantly across countries and industries. The evolution of overall protection in all regions of the world is predominantly driven by changes in NTM protection, while tariff levels are stable or modestly falling over time. This is also reflected when countries are grouped along income lines. Though these non-tariff protectionist measures have fluctuated over time both for regional and income groupings, there has been a tendency towards an increase in recent years. The level of AVEs of NTMs on manufacturing products is generally lower than on agricultural products, but there is an evident increase over time in NTM barriers in manufacturing trade.

Given the findings of this study on the growing dominance of non-tariff over tariff sources of protection, even greater attention needs to be given to NTMs by trade negotiators, policy makers, and multilateral agencies such as the WTO, World Bank and IMF.

Open Access This article is distributed under the terms of the Creative Commons Attribution 4.0 International License (http://creativecommons.org/licenses/by/4.0/), which permits unrestricted use, distribution, and reproduction in any medium, provided you give appropriate credit to the original author(s) and the source, provide a link to the Creative Commons license, and indicate if changes were made.

\section{Appendix}

See Tables 5, 6, 7, 8, 9, 10 and Figs. 4, 5. 
Table 5 Average AVEs of NTMs for each country and year

\begin{tabular}{|c|c|c|c|c|c|c|c|c|}
\hline \multirow[t]{2}{*}{ Country } & \multirow[t]{2}{*}{ ISO3 } & \multicolumn{7}{|l|}{ Year } \\
\hline & & 1997 & 2000 & 2003 & 2006 & 2009 & 2012 & 2015 \\
\hline Afghanistan & AFG & & & & & 0.61 & 0.68 & 0.57 \\
\hline Argentina & ARG & 0.47 & 0.53 & 0.29 & 0.40 & 0.63 & 0.64 & 0.77 \\
\hline Australia & AUS & & & 0.01 & 0.01 & 0.01 & 0.01 & 0.01 \\
\hline Austria & AUT & & & 0.02 & 0.02 & 0.55 & 0.24 & 0.64 \\
\hline Belgium & BEL & & & 0.02 & 0.02 & 0.55 & 0.23 & 0.63 \\
\hline Benin & BEN & & & & & & 0.66 & 0.84 \\
\hline Burkina Faso & BFA & & 0.61 & 0.85 & 0.60 & 0.78 & 0.56 & 0.82 \\
\hline Bulgaria & BGR & & & & & 0.61 & 0.33 & 0.70 \\
\hline Bolivia & BOL & 0.37 & 0.63 & 0.45 & 0.56 & 0.77 & 0.66 & 0.79 \\
\hline Brazil & BRA & 0.39 & 0.44 & 0.30 & 0.41 & 0.59 & 0.68 & 0.76 \\
\hline Brunei Darussalam & BRN & 0.07 & 0.51 & 0.61 & 0.42 & & 0.29 & 0.66 \\
\hline Canada & CAN & & & 0.35 & 0.39 & 0.59 & 0.39 & 0.72 \\
\hline Chile & CHL & 0.31 & 0.58 & 0.44 & 0.36 & 0.59 & 0.35 & 0.76 \\
\hline China & CHN & 0.38 & 0.62 & 0.71 & 0.46 & 0.64 & 0.61 & 0.75 \\
\hline Cote d'Ivoire & CIV & 0.61 & 0.66 & 0.41 & 0.64 & 0.87 & 0.11 & 0.09 \\
\hline Colombia & $\mathrm{COL}$ & 0.14 & 0.20 & 0.28 & 0.32 & 0.46 & 0.39 & 0.59 \\
\hline Cabo Verde & CPV & & & & 0.00 & 0.71 & 0.23 & 0.00 \\
\hline Costa Rica & CRI & 0.07 & 0.13 & 0.19 & 0.17 & 0.28 & 0.12 & 0.22 \\
\hline Cuba & CUB & & 0.74 & 0.46 & 0.65 & & & \\
\hline Cyprus & CYP & & & 0.73 & 0.45 & 0.70 & 0.34 & 0.72 \\
\hline Czech Republic & CZE & & & 0.02 & 0.02 & 0.55 & 0.26 & 0.65 \\
\hline Germany & DEU & & & 0.02 & 0.02 & 0.54 & 0.34 & 0.67 \\
\hline Denmark & DNK & & & 0.02 & 0.02 & 0.59 & 0.27 & 0.66 \\
\hline Dominican Republic & DOM & & & & & & 0.00 & 0.00 \\
\hline Ecuador & ECU & 0.15 & 0.23 & 0.42 & 0.37 & 0.62 & 0.45 & 0.68 \\
\hline Egypt, Arab Rep. & EGY & 0.05 & 0.54 & 0.62 & 0.53 & 0.69 & 0.58 & 0.71 \\
\hline Spain & ESP & & & 0.60 & 0.44 & 0.62 & 0.38 & 0.70 \\
\hline Estonia & EST & & & 0.01 & 0.02 & 0.58 & 0.24 & 0.64 \\
\hline Finland & FIN & & & 0.02 & 0.03 & 0.59 & 0.25 & 0.70 \\
\hline France & FRA & & & 0.02 & 0.02 & 0.54 & 0.32 & 0.67 \\
\hline United Kingdom & GBR & & & 0.02 & 0.02 & 0.56 & 0.41 & 0.67 \\
\hline Ghana & GHA & & 0.08 & 0.28 & 0.19 & 0.28 & 0.17 & 0.78 \\
\hline Guinea & GIN & & & & 0.64 & 0.95 & & \\
\hline Gambia, The & GMB & & & 0.63 & & 0.76 & 0.16 & 0.17 \\
\hline Greece & GRC & & & 0.02 & 0.03 & 0.58 & 0.43 & 0.70 \\
\hline Guatemala & GTM & 0.10 & 0.14 & 0.23 & 0.15 & 0.29 & 0.17 & 0.21 \\
\hline Hong Kong SAR China & HKG & 0.43 & 0.59 & 0.67 & 0.38 & 0.63 & 0.24 & 0.69 \\
\hline Honduras & HND & 0.08 & 0.17 & 0.30 & 0.16 & 0.27 & 0.13 & 0.19 \\
\hline Croatia & HRV & & & & & & 0.29 & 0.67 \\
\hline Hungary & HUN & & & 0.02 & 0.02 & 0.56 & 0.32 & 0.65 \\
\hline Indonesia & IDN & 0.06 & 0.44 & 0.58 & 0.43 & 0.58 & 0.39 & 0.65 \\
\hline
\end{tabular}


Table 5 (continued)

\begin{tabular}{|c|c|c|c|c|c|c|c|c|}
\hline \multirow[t]{2}{*}{ Country } & \multirow[t]{2}{*}{ ISO3 } & \multicolumn{7}{|l|}{ Year } \\
\hline & & 1997 & 2000 & 2003 & 2006 & 2009 & 2012 & 2015 \\
\hline India & IND & 0.06 & 0.06 & 0.12 & 0.12 & 0.23 & 0.66 & 0.74 \\
\hline Ireland & IRL & & & 0.02 & 0.02 & 0.58 & 0.33 & 0.66 \\
\hline Israel & ISR & & & 0.52 & 0.42 & 0.68 & 0.30 & 0.68 \\
\hline Italy & ITA & & & 0.07 & 0.10 & 0.55 & 0.37 & 0.67 \\
\hline Jamaica & JAM & & & 0.00 & 0.00 & 0.00 & 0.00 & \\
\hline Japan & JPN & 0.04 & 0.07 & 0.04 & 0.06 & 0.07 & 0.05 & 0.05 \\
\hline Kazakhstan & KAZ & & & & 0.15 & 0.23 & 0.29 & 0.34 \\
\hline Cambodia & KHM & & & 0.49 & 0.32 & 0.94 & 0.80 & 0.96 \\
\hline Korea, Rep. & KOR & & & 0.05 & 0.06 & 0.06 & 0.05 & 0.05 \\
\hline Lebanon & LBN & 0.00 & 0.74 & 0.64 & 0.46 & 0.68 & 0.21 & 0.70 \\
\hline Sri Lanka & LKA & & 0.65 & 0.77 & 0.47 & 0.66 & 0.32 & 0.74 \\
\hline Lithuania & LTU & & & 0.01 & 0.02 & 0.63 & 0.32 & 0.69 \\
\hline Luxembourg & LUX & & & 0.02 & 0.02 & 0.66 & 0.23 & 0.70 \\
\hline Latvia & LVA & & & 0.02 & 0.02 & 0.62 & 0.26 & 0.69 \\
\hline Morocco & MAR & 0.39 & 0.76 & 0.80 & 0.50 & 0.72 & 0.36 & 0.72 \\
\hline Madagascar & MDG & & 0.33 & 0.43 & 0.35 & 0.46 & 0.43 & 0.25 \\
\hline Mexico & MEX & 0.10 & 0.17 & 0.24 & 0.27 & 0.43 & 0.35 & 0.46 \\
\hline Mali & MLI & 0.51 & 0.02 & 0.80 & 0.63 & 0.79 & 0.87 & \\
\hline Malta & MLT & & & 0.11 & 0.12 & 0.66 & 0.31 & 0.00 \\
\hline Mauritius & MUS & 0.15 & 0.37 & 0.48 & 0.27 & 0.46 & 0.15 & 0.21 \\
\hline Malawi & MWI & 0.29 & 0.20 & 0.34 & 0.22 & 0.33 & 0.19 & 0.23 \\
\hline Malaysia & MYS & 0.10 & 0.54 & 0.51 & 0.38 & 0.59 & 0.33 & 0.66 \\
\hline Niger & NER & & & 0.65 & 0.66 & 0.80 & 0.62 & 0.82 \\
\hline Nigeria & NGA & & & & 0.57 & 0.77 & 0.88 & 0.80 \\
\hline Nicaragua & NIC & 0.09 & 0.18 & 0.28 & 0.15 & 0.28 & 0.14 & 0.18 \\
\hline Netherlands & NLD & & & 0.02 & 0.02 & 0.54 & 0.27 & 0.64 \\
\hline Nepal & NPL & & 0.56 & 0.85 & & 0.73 & 0.49 & 0.77 \\
\hline New Zealand & NZL & & & 0.01 & 0.01 & 0.01 & 0.01 & 0.01 \\
\hline Pakistan & PAK & & & 0.01 & 0.01 & 0.50 & 0.59 & 0.55 \\
\hline Panama & PAN & 0.09 & 0.16 & 0.30 & 0.28 & 0.43 & 0.26 & 0.00 \\
\hline Peru & PER & 0.16 & 0.31 & 0.35 & 0.36 & 0.55 & 0.39 & 0.70 \\
\hline Philippines & PHL & 0.42 & 0.52 & 0.67 & 0.54 & 0.70 & 0.65 & 0.76 \\
\hline Poland & POL & & & 0.02 & 0.02 & 0.56 & 0.35 & 0.66 \\
\hline Portugal & PRT & & & 0.54 & 0.41 & 0.62 & 0.36 & 0.67 \\
\hline Paraguay & PRY & 0.31 & 0.62 & 0.55 & 0.51 & 0.75 & 0.70 & 0.78 \\
\hline Romania & ROM & & & & & 0.59 & 0.33 & 0.70 \\
\hline Russian Federation & RUS & & & & 0.03 & 0.61 & 0.50 & 0.70 \\
\hline Rwanda & RWA & 0.31 & 0.21 & 0.39 & 0.33 & 0.47 & 0.24 & 0.35 \\
\hline Senegal & SEN & & 0.61 & 0.80 & 0.55 & 0.75 & 0.50 & 0.81 \\
\hline Singapore & SGP & 0.06 & 0.61 & 0.70 & 0.44 & 0.65 & 0.25 & 0.69 \\
\hline El Salvador & SLV & 0.08 & 0.14 & 0.20 & 0.14 & 0.27 & 0.16 & 0.20 \\
\hline
\end{tabular}


Table 5 (continued)

\begin{tabular}{lllllllll}
\hline Country & ISO3 & \multicolumn{2}{l}{ Year } & & & & & \\
\cline { 4 - 8 } & & 1997 & 2000 & 2003 & 2006 & 2009 & 2012 & 2015 \\
\hline Slovak Republic & SVK & & & & 0.02 & 0.57 & 0.27 & 0.66 \\
Slovenia & SVN & & & 0.02 & 0.02 & 0.60 & 0.26 & 0.66 \\
Sweden & SWE & & & 0.02 & 0.02 & 0.57 & 0.25 & 0.65 \\
Togo & TGO & 0.38 & 0.55 & 0.74 & 0.60 & 0.80 & 0.11 & 0.12 \\
Thailand & THA & & 0.19 & 0.29 & 0.21 & 0.62 & 0.41 & 0.73 \\
Trinidad and Tobago & TTO & & 0.00 & 0.00 & 0.00 & 0.00 & 0.00 & \\
Tunisia & TUN & 0.04 & 0.07 & 0.10 & 0.11 & 0.60 & 0.36 & 0.72 \\
Turkey & TUR & 0.08 & 0.66 & 0.39 & 0.43 & 0.63 & 0.47 & 0.73 \\
Tanzania & TZA & & & & & 0.49 & 0.38 & 0.37 \\
Ukraine & UKR & & & 0.01 & 0.03 & 0.63 & 0.47 & 0.71 \\
Uruguay & URY & 0.40 & 0.60 & 0.45 & 0.46 & 0.69 & 0.39 & 0.82 \\
United States & USA & & & 0.27 & 0.37 & 0.57 & 0.61 & 0.74 \\
Venezuela, RB & VEN & 0.07 & 0.12 & 0.12 & 0.14 & 0.20 & 0.14 & 0.28 \\
Vietnam & VNM & & & & 0.51 & 0.71 & 0.58 & 0.78 \\
South Africa & ZAF & & & 0.01 & 0.01 & 0.01 & 0.00 & 0.00 \\
\hline
\end{tabular}

Table 6 Percentage of product lines with tariff rate greater, equal to and smaller than AVE of NTMs for products subject to core NTM, by year

\begin{tabular}{llll}
\hline Year & Tariff $>$ NTM $(\%)$ & $\begin{array}{l}\text { Tariff }=\text { NTM } \\
(\%)\end{array}$ & Tariff $<$ NTM $(\%)$ \\
\hline 1997 & 43.87 & 4.65 & 51.48 \\
2000 & 26.81 & 3.16 & 70.03 \\
2003 & 20.72 & 2.06 & 77.22 \\
2006 & 35.27 & 6.58 & 58.15 \\
2009 & 17.86 & 1.69 & 80.45 \\
2012 & 28.15 & 5.17 & 66.68 \\
2015 & 27.27 & 6.31 & 66.41 \\
\hline
\end{tabular}

Table 7 Comparison with estimates of Kee et al. (2009)

\begin{tabular}{lllll}
\hline ISO3 & Year & Observations & $\begin{array}{l}\text { Simple average of AVEs of } \\
\text { NTM }\end{array}$ \\
\cline { 4 - 5 } & & & Our estimates & $\begin{array}{l}\text { Kee et al. } \\
\text { estimates }\end{array}$ \\
\hline ARG & 2003 & 4131 & 0.34 & 0.53 \\
AUS & 2003 & 4630 & 0.47 & 0.55 \\
AUT & 2003 & 4755 & 0.28 & 0.65 \\
BFA & 2003 & 1313 & 0.88 & 0.54 \\
BOL & 2003 & 2796 & 0.59 & 0.55 \\
BRA & 2003 & 4378 & 0.31 & 0.58 \\
BRN & 2003 & 3869 & 0.40 & 0.58 \\
\hline
\end{tabular}


Table 7 (continued)

\begin{tabular}{|c|c|c|c|c|}
\hline \multirow[t]{2}{*}{ ISO3 } & \multirow[t]{2}{*}{ Year } & \multirow[t]{2}{*}{ Observations } & \multicolumn{2}{|c|}{$\begin{array}{l}\text { Simple average of AVEs of } \\
\text { NTM }\end{array}$} \\
\hline & & & Our estimates & $\begin{array}{l}\text { Kee et al. } \\
\text { estimates }\end{array}$ \\
\hline CAN & 2003 & 4774 & 0.27 & 0.47 \\
\hline CHL & 2003 & 3934 & 0.44 & 0.43 \\
\hline $\mathrm{CHN}$ & 2003 & 4617 & 0.56 & 0.47 \\
\hline CIV & 2003 & 2317 & 0.34 & 0.59 \\
\hline COL & 2003 & 4126 & 0.44 & 0.47 \\
\hline CRI & 2003 & 3488 & 0.58 & 0.48 \\
\hline $\mathrm{CZE}$ & 2003 & 4651 & 1.11 & 0.29 \\
\hline DEU & 2003 & 4809 & 0.35 & 0.59 \\
\hline DNK & 2003 & 4725 & 0.26 & 0.63 \\
\hline EGY & 2003 & 3646 & 0.50 & 0.55 \\
\hline ESP & 2003 & 4805 & 0.38 & 0.58 \\
\hline FIN & 2003 & 4650 & 0.32 & 0.61 \\
\hline FRA & 2003 & 4807 & 0.28 & 0.65 \\
\hline GBR & 2003 & 4798 & 0.34 & 0.56 \\
\hline GHA & 2003 & 2617 & 0.74 & 0.50 \\
\hline GRC & 2003 & 4711 & 0.29 & 0.70 \\
\hline GTM & 2003 & 3951 & 0.53 & 0.51 \\
\hline HKG & 2003 & 4893 & 0.53 & 0.43 \\
\hline HND & 2003 & 3374 & 0.89 & 0.54 \\
\hline HUN & 2003 & 4317 & 0.48 & 0.44 \\
\hline IDN & 2003 & 4490 & 0.51 & 0.59 \\
\hline IND & 2003 & 4039 & 0.55 & 0.51 \\
\hline IRL & 2003 & 4670 & 0.24 & 0.71 \\
\hline ITA & 2003 & 4807 & 0.26 & 0.61 \\
\hline JPN & 2003 & 4791 & 0.16 & 0.51 \\
\hline KOR & 2003 & 4627 & 0.78 & 0.21 \\
\hline LBN & 2003 & 3801 & 0.56 & 0.56 \\
\hline LKA & 2003 & 3494 & 0.90 & 0.42 \\
\hline LTU & 2003 & 4469 & 0.57 & 0.51 \\
\hline LVA & 2003 & 3727 & 0.54 & 0.55 \\
\hline MAR & 2003 & 3696 & 0.65 & 0.49 \\
\hline MDG & 2003 & 2475 & 0.61 & 0.51 \\
\hline MEX & 2003 & 4570 & 0.32 & 0.46 \\
\hline MLI & 2003 & 1217 & 0.86 & 0.59 \\
\hline MUS & 2003 & 3542 & 0.72 & 0.56 \\
\hline MWI & 2003 & 1951 & 0.80 & 0.65 \\
\hline MYS & 2003 & 4835 & 0.46 & 0.46 \\
\hline NIC & 2003 & 3502 & 0.76 & 0.58 \\
\hline NLD & 2003 & 4793 & 0.37 & 0.60 \\
\hline NZL & 2003 & 4531 & 0.63 & 0.52 \\
\hline
\end{tabular}


Table 7 (continued)

Table 8 Average AVE of NTMs for lagged policy variables, by year

\begin{tabular}{|c|c|c|c|c|}
\hline \multirow[t]{2}{*}{ ISO3 } & \multirow[t]{2}{*}{ Year } & \multirow[t]{2}{*}{ Observations } & \multicolumn{2}{|c|}{$\begin{array}{l}\text { Simple average of AVEs of } \\
\text { NTM }\end{array}$} \\
\hline & & & Our estimates & $\begin{array}{l}\text { Kee et al. } \\
\text { estimates }\end{array}$ \\
\hline PER & 2003 & 3603 & 0.43 & 0.51 \\
\hline PHL & 2003 & 4086 & 0.57 & 0.52 \\
\hline POL & 2003 & 4287 & 0.26 & 0.46 \\
\hline PRT & 2003 & 4734 & 0.37 & 0.65 \\
\hline PRY & 2003 & 2749 & 0.58 & 0.64 \\
\hline RWA & 2003 & 971 & 1.02 & 0.76 \\
\hline SEN & 2003 & 2128 & 0.73 & 0.61 \\
\hline SGP & 2003 & 4875 & 0.63 & 0.51 \\
\hline SLV & 2003 & 4049 & 0.46 & 0.59 \\
\hline SVN & 2003 & 4398 & 0.48 & 0.53 \\
\hline SWE & 2003 & 4716 & 0.32 & 0.57 \\
\hline THA & 2003 & 4349 & 0.50 & 0.53 \\
\hline TUN & 2003 & 3712 & 0.66 & 0.50 \\
\hline TUR & 2003 & 4476 & 0.40 & 0.48 \\
\hline UKR & 2003 & 3958 & 0.59 & 0.53 \\
\hline URY & 2003 & 3151 & 0.44 & 0.57 \\
\hline USA & 2003 & 4757 & 0.24 & 0.52 \\
\hline VEN & 2003 & 4234 & 0.48 & 0.47 \\
\hline ZAF & 2003 & 4650 & 0.45 & 0.45 \\
\hline
\end{tabular}

This is the comparison of our estimates with Kee et al. estimation among the sample for which both our estimations are non-missing. So the sample size here is smaller than our full sample

\begin{tabular}{llll}
\hline Year & $\begin{array}{l}\text { No. of Coun- } \\
\text { tries } \\
(1)\end{array}$ & Mean (SD) & $\begin{array}{l}\text { Correlation with } \\
\text { original results } \\
(3)\end{array}$ \\
\hline 2000 & 37 & $0.24(0.68)$ & 0.36 \\
2003 & 46 & $0.34(0.80)$ & 0.42 \\
2006 & 81 & $0.27(0.71)$ & 0.53 \\
2009 & 88 & $0.32(0.77)$ & 0.41 \\
2012 & 92 & $0.65(0.97)$ & 0.41 \\
2015 & 92 & $0.59(0.95)$ & 0.75 \\
\hline
\end{tabular}


Table 9 Correlation matrix of incidence of core NTMs

\begin{tabular}{llllllll}
\hline & 1997 & 2000 & 2003 & 2006 & 2009 & 2012 & 2015 \\
\hline 1997 & 1 & & & & & & \\
2000 & 0.7228 & 1 & & & & & \\
2003 & 0.632 & 0.8678 & 1 & & & & \\
2006 & 0.5604 & 0.7764 & 0.8968 & 1 & & & \\
2009 & 0.5346 & 0.7355 & 0.848 & 0.9427 & 1 & & \\
2012 & 0.4247 & 0.6046 & 0.7018 & 0.7763 & 0.8217 & 1 & \\
2015 & 0.4118 & 0.5552 & 0.6504 & 0.7199 & 0.7628 & 0.9218 & 1 \\
\hline
\end{tabular}

Table 10 Results for AVE of NTMs with Balanced Sample of Countries, by Year

\begin{tabular}{llllll}
\hline Year & $\begin{array}{l}\text { No. of countries } \\
\text { with balanced } \\
\text { sample } \\
(1)\end{array}$ & $\begin{array}{l}\text { Balanced } \\
\text { Sample Mean } \\
(\text { SD) } \\
(2)\end{array}$ & $\begin{array}{l}\text { No. of countries } \\
\text { with original } \\
\text { sample } \\
(3)\end{array}$ & $\begin{array}{l}\text { Original } \\
\text { Sample Mean } \\
(\text { SD) } \\
(4)\end{array}$ & $\begin{array}{l}\text { Correlation of } \\
\text { estimates between } \\
\text { samples } \\
(5)\end{array}$ \\
\hline 2003 & 76 & $0.24(0.61)$ & 83 & $0.27(0.64)$ & 0.86 \\
2006 & 76 & $0.23(0.60)$ & 88 & $0.22(0.64)$ & 0.55 \\
2009 & 76 & $0.49(0.83)$ & 92 & $0.52(0.85)$ & 0.75 \\
2012 & 76 & $0.35(0.73)$ & 95 & $0.33(0.71)$ & 0.68 \\
2015 & 76 & $0.46(0.87)$ & 92 & $0.57(0.95)$ & 0.70 \\
\hline
\end{tabular}

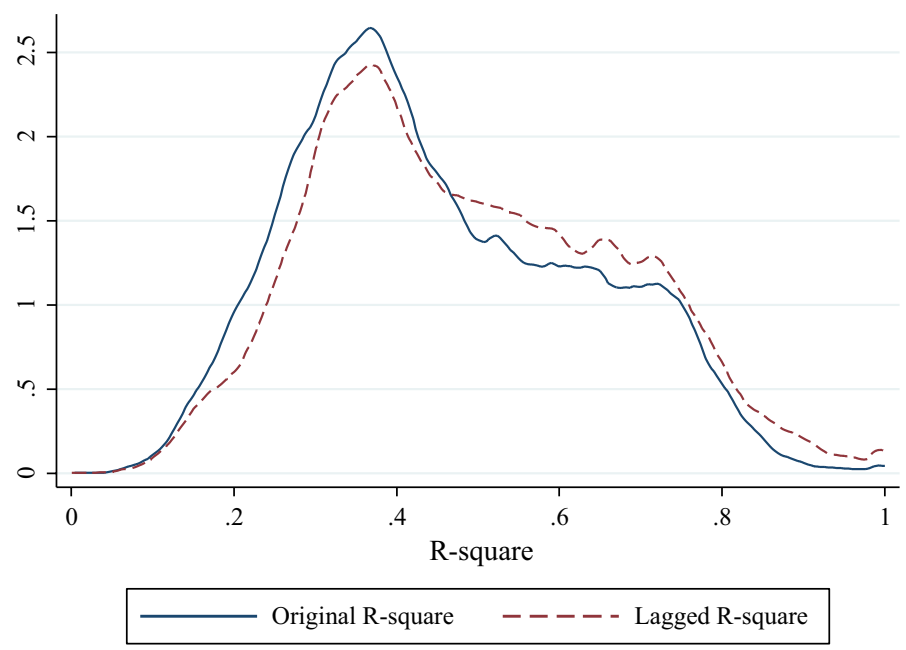

Fig. 4 R-squares from the estimated regressions with contemporaneous and lagged policy variables 


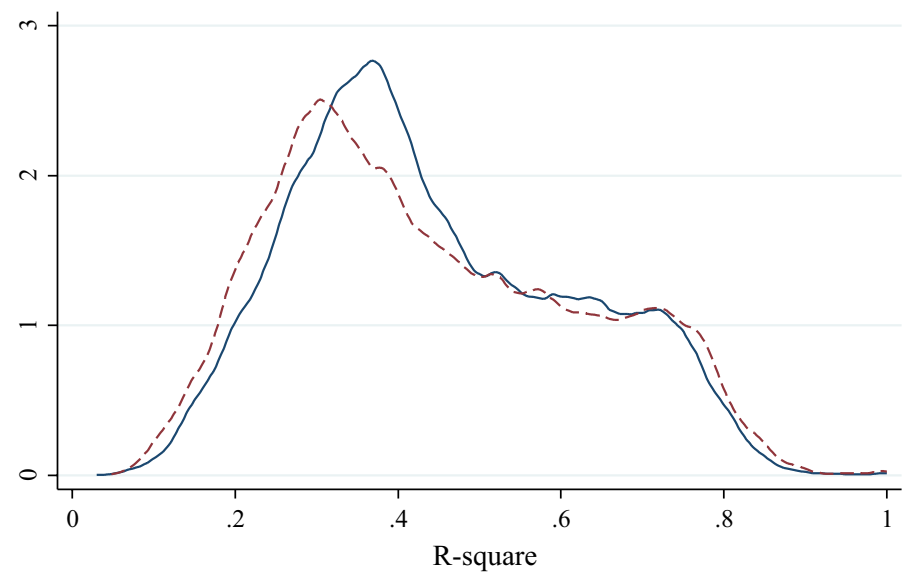

Original R-square $\quad-----$ Balanced R-square

Fig. 5 R-squares from the estimated regressions with non-balanced and balanced samples

\section{References}

Aisbett, E., \& Pearson, L. M. (2013). Environmental and health protections, or new protectionism? Determinants of SPS notifications by WTO members. Crawford School Research Paper (pp. 12-13).

Anderson, J. E., \& Neary, J. P. (1994). Measuring the restrictiveness of trade policy. World Bank Economic Review, 8(2), 151-169.

Anderson, J. E., \& Neary, J. P. (1996). A new approach to evaluating trade policy. Review of Economic Studies, 63(1), 107-125.

Balassa, B. (1965). Tariff protection in industrial countries: An evaluation. Journal of Political Economy, 73, 573-594.

Baldwin, R. E. (1991). Measuring nontariff trade policies. In J. De Melo \& A. Sapir (Eds.), Trade theory and economic reform. Oxford: Basil Blackwell.

Bora, B. K., Kuwahara, A., \& Laird, S. (2002). Quantification on non-tariff measures. Geneva: United Nations Publication.

Bouet, A., Decreux, Y., Fontagne, L., Jean, S., \& Laborde, D. (2008). Assessing applied protection across the world. Review of International Economics, 16(5), 850-863.

Bowen, H. P., Hollander, A., \& Viaene, J.-M. (2016). Applied international trade (2nd ed.). Hampshire: Palgrave Macmillan.

Bradford, S. (2003). Paying the price: Final goods protection in OECD countries. Review of Economics and Statistics, 85(1), 24-37.

Bratt, M. (2017). Estimating the bilateral impact of nontariff measures on trade. Review of International Economics, 25(1), 1-25.

Corden, W. M. (1966). The structure of a tariff system and the effective protective rate. Journal of Political Economy, 74(3), 221-237.

Dean, J. M., Signoret, J. E., Feinberg, R. M., Ludema, R. D., \& Ferrantino, M. J. (2009). Estimating the price effects of non-tariff barriers. BE Journal of Economic Analysis \& Policy, 9(1), 1935-1682.

Deardorff, A. V., \& Stern, R. M. (1998). Measurement of nontariff barriers. Ann Harbor: University of Michigan Press.

Disdier, A.-C., \& Marette, S. (2010). The combination of gravity and welfare approaches for evaluating nontariff measures. American Journal of Agricultural Economics, 92(3), 713-726. 
Ferrantino, M. (2006). Quantifying the trade and economic effects of non-tariff measures. Paris: OECD Publishing.

Ganslandt, M., \& Markusen, J. R. (2001). Standards and related regulations in international trade: A modeling approach. In E. M. Keith \& S. W. John (Eds.), Quantifying the impact of technical barriers to trade: Can it be done?. Ann Harbor: University of Michigan Press.

Hoekman, B., Ng, F., \& Olarreaga, M. (2004). Agricultural tariffs or subsidies: Which are more important for developing economies? World Bank Economic Review, 18(2), 175-204.

Kee, H. L., Neagu, C., \& Nicita, A. (2013). Is protectionism on the rise? Assessing national trade policies during the crisis of 2008. Review of Economics and Statistics, 95(1), 342-346.

Kee, H. L., Nicita, A., \& Olarreaga, M. (2008). Import demand elasticities and trade distortions. Review of Economics and Statistics, 90(4), 666-682.

Kee, H. L., Nicita, A., \& Olarreaga, M. (2009). Estimating trade restrictiveness indices. Economic Journal, $119(534), 172-199$.

Leamer, E. E. (1988). Measures of openness. In Trade policy issues and empirical analysis (pp. 145-204). Chicago: University of Chicago Press.

Leamer, E. E. (1990). Latin America as a target of trade barriers erected by the major developed countries in 1983. Journal of Development Economics, 32(2), 337-368.

Lee, J.-W., \& Swagel, P. (1997). Trade barriers and trade flows across countries and industries. Review of Economics and Statistics, 79(3), 372-382.

Nicita, A., \& Gourdon, J. (2013). A preliminary analysis on newly collected data on non-tariff measures 1607-8291. New York: UNCTAD.

Trefler, D. (1993). Trade liberalization and the theory of endogenous protection: An econometric study of US import policy. Journal of Political Economy, 101(1), 138-160.

UNCTAD. (2010). Non-tariff measures: Evidence from selected developing countries and future research agenda. New York: UNCTAD.

WTO. (2012). World trade report 2012-Trade and public policies: A closer look at non-tariff measures in the 21st century. Geneva: World Trade Organization. 